\title{
Docencia Jurídica y Estado de Derecho
}

\author{
Por el Doctor RAUL FERRERO,
}

Catedrático titular de Derecho Constitucional, en la Pontificia Universidad Católica de Lima.

La apertura del año universitario es ocasión indicada para que los docentes del claustro inquieran, sin interferencias de valoraciones contingentes, qué correspondencia existe entre su estilo de pensamiento y la aplicación de loa conocimientos que difunden. Un pensar y un querer unitivos debieran ser el logro de la Universidad, puesta al servicio de la cultura $Y$ de la sociedad. Ios matices diferenciales que distinguen a cada catedrático, y aún lás propias contradicciones, enervan muy poco tal orientación doctrinaria, que prơiene de una común visión del mundo y del hombre. La estructura lógica de maestros y alumnos deviene en conducta inexcusable, pues el modo de pensar es normativo y la experiencia cotidiana ha de ser trasunto de verdades racionales, derivadas de una ley eterna, como reverberación de una realidad superior.

La valoración jurídica no reside solamente en el juez o en el legislador. Do modo más o menos certero, la ejerce cada persona en su fuero íntimo, f.or virtud de una estimativa natural que es el resplandor de la luz divina. La docencia jurídica, aplicada directamente a los futuros hombres de ley. trasciende del ámbito académico a la vida general porque la imagen de lo jurídico no es privativo de abogados y políticos sino fundamento moral de la conducta común. La diferencia radica únicamente en que los hombres instruidos y la masa aplican un criterio simplista, en tanto que las mentes consagradas a la enseñanza del derecho se esfuerzan por descubrir las conexiones ideológicas entre la vida y la ley, a fin de dar a las normas jurídicas un fundamento superior a la voluntad del gobernante, trátese de un partido o de un hombre.

Racionalizar el poder es atribuir el gobierno a la objetividad de la norma, impersonalizada y desnuda de intereses, dentro de una arquitectura social que llamamos Estado de Derecho. En la hora agonal que vive el mundo, examinemos la inserción de la persona humana en la institución política que denominamos el Estado y comencemos por remontarnos hacia las

(1) Discurso de Orden, con ocasión de la Apertura del Año Académico de 1958. 
fuentes del Estado de Derecho en el Perú. Veremos así, en el descrrollo de la exposición, por qué nuestra misión docente está transida de sentido, engarzada en la dialéctica social, querrámoslo o no, e impregnada de una dignidad creadora que nos une al alumno, que nos asocia a él con una ligazón cordial, conscientes de que la Universidad existe para ellos y de que ia torea del profesor trasciende del mero dictado de las clases.

La comunión de voluntades comienza en el Perú con la aparición re la conciencia nacional, por obra de la filosofía de la Ilustración, en aquella década de 1780 a 1790 que se inicia con el levantamiento de Túpac Amaru y con la renovación intelectual del Virreynato. Los jóvenes nacidos eu esos años, como Mariátegui, Sánchez Carrión, Luna Pizarro, Arre, Lazo y González Vigil, se educaron en Lima bajo la dirección de Rodríguez de Mendoza y en Arequipa bajo el episcopado de Chávez de la Rosa. Como dice Raúl Porras formaron una generación predestinada. "El estallido revolucionario los hallará a los 30 años, maduros ya para el pensamiento de la libertad, pero todavía con la pasión y el arrebato juveniles necesanos para la acción y para el sacrificio". En el Convictorio de San Carlos, Rodríguez de Mendoza desterró la enseñanza escolástica y modernizó la instrucción en las ciencias físicas y naturales mediante la exposición de Newton y Descartes. En filosofía y derecho, implantó la obra del jurista germano Heinecio, con lo que dió a conocer lơs ideas de Wolff, discípulo de Leibniz y expositor notable de Grocio y Puffendorf. Por ello, cabe afirmar que, al igual que en los Estados Unidos, el derecho natural está en la esencia de nuestra constitución republicana. Desde aquella fase finisecular hasta mediados del siglo XIX continuarían fundiéndose la corriente hispana y la corriente nortermericana del derecho natural. El Perú adquirió conciencia de su singularidad como nación a la luz del jusnaturalismo y haciendo carne los principios invocados por los colonos norteamericanos y luego proclamados por la Revolución Francesa: el derecho a la rebelión, la soberanía nacional y la libre determinación de los pueblos.

Las corrientes imperantes en el Perú de mediados del siglo diecinueve fueron: en política, el liberalismo; en literatura, el romanticismo; en derecho, el Krausismo. Respecto de éste no deja de ser curioso que fuera introducido en la enseñanza por el propio Bartolomé Herrera, el cual implantó en el Convictorio de San Carlos el texto sobre Derecho Natural de Enrique Ahrens, que era divulgador del Krausismo y, por lo tanto, de la escuela del derecho racional originada en el pensamiento de Kant. Sucedió así que una mentalidad religiosa, como la de Herrera, desplazara a un pensador de fundamentación teológica, como Heinecio, para entronizar a un expositor racionalista, el germano Ahrens, simplemente porque nuestros grandes maestros de entonces no conocieron bien las conexiones filosóficas de las escuelas europeas.

Poco después, el mós eminente entre los discípulos y contradictores de Herrera, Pedro Gálvez, llevaría la exposición de Āhrens a los claustros 
del Colegio de Guadalupe, en donde por una década ilustre se sostendría el debate ideológico de los liberales con los doctrinarios conservadores, parapetados a una cuadra de distancia, en el Convictorio de San Carlos, cuando ambos locales se hallaban separados sólo por la huerta que en este siglo vino a ser ocupada por el Parque Universitario. Ampliando la nueva corriente jusnaturalista, José Gálvez implantó en Guadalupo la enseñanza del Derecho Correccional, dando un sentido humano y reformista a la disciplina conocida hasta entoncos como Derecho Penal. En ixl orientación, nuestra primera figura liberal se anticipó al insigne Roder, seguidor igualmente del Krausismo.

El texto de Ahrens, intitulado "Curso Completo de Derecho Natural - de Filosofía del Derecho" fué adoptado también en la Universidad de San Marcos, en donde mantuvo su influencia por cuatro décadas. Luciano Benjamín Cisneros lo utilizó en la cótedra de Derecho Natural, que dejara en 1868, año en que empieza a dictarla Luis Felipe Villarán, el cual atemFeló la tendencia especulativa y difusa del Krausismo, escuela de la que Ahrens, pese a su modesta elevación intelectual, había sido eficaz divulgador en Bélgica, como profesor de la Universidad de Bruselas, con resonancia en Francia y España, y luego en Austria, como profesor de la Universidad de Gratz.

Kirause, injustamente censurado por Menéndez y Pelayo, que lo llamó "metafísico de institutrices", alcanzó en España una influencia formidable. Su sistema panteista, con ramificaciones jurídicas concebía el universo como una síntesis de la razón humana y de la naturaleza. Era un liberalismo inspirado en la dirección humanista de Humboldt y habría de pre dominar en la enseñanza superior de nuesto país, gracias al texto de Derecho Natural de Ahrens hasta 1896, año en que Manuel Vicente Villarán introdujo en la Universidad de San Marcos el pensamiento positivista. Resulta curioso anotar que aquí mantuvimos a Ahrens en la enseñanza varias décadas respués de haber sido abandonado en Europa y cuando el historicismo juriacio de Savigny imperaba como imbatible.

La figura más brillante que tuvo el liberalismo peruano, Enrique Alvarado, advirtió que las leciones dictadas por Pedro Gálvez en la Facultad de Jurisprudencia "acusaban la influencia del panteísmo idealista, con reminiscencias de Kant y Fichte", según relieva Salazar Bondy. Y este mismo autor afirma que Deustua, al abandonar su actitud inicial y reaccionar contra la concepción positivista y mecanicista del mundo, encarnando la reacción espi1itualista, aprovechó en este siglo motivos del pensamiento Krousista para :orjar una doctrina estética fundada en la vivencia de la libertad. El que la tilnsofía Krousista fuera retomada, aunque parcialmente, años después de hxber perdido toda vigencia en la enseñanza de los supuestos fundamentales del Derecho, hace patente cuan profunda y dilatada influencia logró el Kıcusismo en nuestro medio.

Medio siglo antes de que Villarán, defensor de las libertades humanas, se cpartara del idealismo de Kant y también del evolucionismo spencestano para enseñar que la libertad no puede ser el único contenido del derecho y que, si bien la justicia exige la libertad, ésta no basta para asegurar la 
realización de aquella, nuestros liberales eran apasionadarmente adictos $\alpha$ la convicción progresista. Según ella la libertad es un fin y basta por si sola para realizar una feliz coexistencia entre los hombres. La generación liberal del 56, contagiada de romanticismo $Y$ de Krausismo, creyó como Ahrens que el derecho debía ser influído preponderantemente por el sentimiento de libertad y que la organización social deviene espontánea y requiere muy poca coacción.

El Krausismo fue cultivado en España principalmente por Julián Sanz del Río, cuya actividad docente determinó una notable floración intelectual. Su magisterio, como proclama con entusiasmo Recasens Siches, alcanzó superlativas dimensiones e influyó en que el Krausismo trascendiera los cauces universitarios y conmoviera toda la vida intelectual del país. La actiiud de los Krausistas, salvadas diferencias individuales o de escuelas, era común en cuanto racionalista y progresista. Por razón de cronología, es de suponerse que la obra de Sanz del Río influyera indirectamente en nuestro merio, no así la de Francisco Giner de los Ríos, su notable discípulo y aventajado continuador. Sin embargo de la diferencia, la actitud de nuestros liberales corresponde al pensamiento de Giner de los Ríos, imbuído de un sentido vital de acción e inspirado en el principio generoso de que la espiritualidad personal no ha de servir solamente para nuestra propia satisfacción sino que debe ser derramada sobre "los intinitos parias del ideal" para ayudarles $\alpha$ ascender.

La influencia del Krausismo llegó de España al Perú a través de las obras de Pacheco, Alcalá Guillermo, García Goyena y Cortina; pero fue la "Filosofía del Derecho" de Ahrens, en traducción de Navarro Zamorano, la mayor fuente de consulta en las universidades de Hispano-América.

Francisco García Calderón incorporó a su obra monumental, "Diccionario de la Legislación Peruana", la doctrina del derecho racional, definiendo el derecho natural como el conjunto de principios fijos que el hombre descubre examinando con su razón su propia naturaleza, o sea que el derecho es una idea que precede a la experiencia y la trasciende, es un principio de justicia del que se deducen las verdades jurídicas particulares.

Ahora es útil aludir a la posterior evolución de las ideas, a fin de completar la reconstrucción del derrotero de la enseñanza filosófico-jurídica en el Perú. Por eso señalaremos la breve influencia del positivismo, así como la reacción crítica del iusnaturalismo que sobreviene en la segunda década de nuestro siglo y se mantiene hasta hoy, oreada por el movimiento intelectual europeo y por el nuevo triunfo de la metafísica sobre el saber experimental.

El positivismo, que iba a presentar las fases política, educativa $Y$ jurídica, llegó algo retrasado el Perú y no alcanzó la importancia que tuvo en otros países latinoamericanos, como México, Chile y Brasil. La guerra con Chile, que determinó nuestro empobrecimiento pasajero, contribuyó a la aminoración de la influencia positivista, pues dicha corriente ideológica no encontró el progreso industrial y científico que era su necescrio correlato.

El período metafísico de la filosofía jurídica comprende desde el Renacimiento hasta mediados del siglo XIX. La doctrina clásica del derecho natural, 
así como las concepciones históricas del Derecho sostenidas por Savigny, Hegel y Marx se caracterizan por un fuerte elemento metafísico, puesto que tratan de explicar la naturaleza y el significado del Derecho en base a ciertos principios últimos, concebidos como operantes más allá de la superficie empírica de las cosas. La "razón eterna" de los jusnaturalistas, el "espíritu del pueblo" de Savigny, el "espíritu universal" de Hegel o "la desaparición del estado" de Marx, trascienden del mundo empírico y son construcciones metafísicas. Ello fue advertido por el positivismo, que, como actitud científica, rethaza las especulaciones apriorísticas y metafísicas y se confina en los datos de la experiencia.

Como anota Bodenheimer, el auge del positivismo en la segunda mitad del siglo XIX se explica por el éxito que lograron las ciencias naturales, determinando la tentación de aplicar a las ciencias sociales los métodos de las ciencias naturales. Se creyó así que la escuela del derecho natural había idealizado el derecho, al relacionarlo con los conceptos de dignidad, libertad e igualdad humana, a pesar de que tales principios no habían tenido vigencia sino desde fines del siglo XVIII. Los principios eternos, dijo el positivismo, eran postulados pero no realidades. Tales ataques contra el racionalismo histórico no lograron mellar sino por breves décadas la boga del derecho natural, pues, en la práctica, el derecho positivo de hoy sigue siendo el precipitado de las normas del derecho natural y la doctrina constitucional mantiene intucto el principio de que existen reglas jurídicas superiores al poder político y obligatorias para él.

Con todo, el clima intelectual de amargura y reformismo, como en el caso ilustre de González Prada, dió resonancia al pensamiento positivista. En los primeros lustros de este siglo, la fe cientificista y la creencia de que la educación bastaba para reformar la sociedad están patentes en la obra Le Javier Prado y en la de Jorge Polar, que tanta influencia alcanzaran en los dos primeros decenios de nuestro siglo. Manuel Vicente Villarán superó la posición positivista, sin abandonarla, al señalar la importancia de los factores económicos y mantenerse leal a los valores liberales.

La corriente del liberalismo germano fue sustituída, a partir de 1896, por la doctrina inglesa de Stuart Mill y la exposición del sistema jurídico anglo-sajón cuando inició su docencia Villarán. Fue éste un renovador insigne de los estudios jurídicos; a la vez que introducía las obras de Jellinek y Laband, explicaba el pensamiento de Stuart Mill y trasfundía con fervor el mensaje de respeto a la libertad civil entendida como condición necesaria para que la persona humana realice su fin individual. La tendencia positivista de Villarán, preconizador del practicismo y de la técnica en la educación, no alteró su línea liberal, si bien restringió el individualismo exagerado al justificar las limitaciones impuestas por el interés social. En nuestra docencia jurídica merecen un especial relieve el maestro Villarán y su inteligente continuador Juan Baitista de Lavalle. Este último dió a conocer el pensamiento de Icilio Vanni $y$ difundió los principios del derecho natural, fundamentados con gran modernidad por los jusfilósofos italianos y tranceses. Tunto Villarán, como años más tarde Lavalle, pusieron énfasis en el contenido ético del Derecho $\mathrm{y}$ en proclamar como deber del jurista la defensa de 
la libertad conciliada con el orden, puesto que ambos principios son necesarios para realizar el valor supremo: la justicia.

En la Universidad, Ahrens fue desplazado a fin de siglo por el positivismo y el método comparado, introducidos por Manuel Vicente Villarán, maestro eminente cuya lucidez jurídica y sencillez didáctica recordaremos siempre con admiración. El historicismo de Savigny, asi como el utilitarismo social de Thering, de similar sentido histórico, serian introducidos en nuestro sigla por José de la Riva Agüero. Al comienzo de la segunda década, Juan Bautista de Lavalle, continuando el estudio de las fuentes del Derecho que Villarón había estimulado, representó la reacción crítica y iusnaturalista.

Víctor Andrés Belaúnde, desde la cátedra de la Universidad Católica, así como en los debates constitucionales de 1932 y mediante su valiosa obra "Lce crisis presente", contribuyó a difundir la concepción espiritualista de la sociedad, la idea del valor esencial de la persona humana y los principios filosóficos en que reposa el Estado de Derecho. La influencia doctrinaria de Belaúnde en la Universidad Católica ha sido profunda y constructiva y por eso lo acompaña la admiración intelectual y el afecto de sus alumnos de ayer. Belaúnde expuso brillantemente a Hauriou, con lo que repuso en la docencia jurídica los valores relevantes del derecho natural teológico, modernizado por los tomistas actuales. La sustancia religiosa de la vida humana, así como la exigencia de restaurar una cultura orgánica respecto a la cual el Derecho es un aspecto de raíces morales y divinas, constituye el mensaje del maestro Belaúnde.

Durante la centuria que va de la mitad del siglo pasado a nuestros tiempos, la educación superior ha sido disputada por tres tendencias: la concepción católica, fundada en el agustinismo y la escolástica; el idalismo racionalista, derivado del tronco cartesiano y del criticismo de Kant; $\mathrm{y}$ el positivismo, nutrido de espíritu cientificista y burgués. Las tres tendencias han cona cido su período de predominio y el ciclo parece haber terminado con un "Dios a la vista". El positivismo, preocupado solamente de los hechos, consideró que no tenía sentido el estudio de las causas primeras o finales, a pesar de que la idea de causa es innata en el hombre. Las grandes hipótesis que intentan explicar el porqué del universo fueron proscritas por inverificables y se las reputó fantasías de los metafísicos.

Anquilosado por su falta de imaginación y por su empirismo, el positivismo perece por haber desdeñado aquellas ideas humanísticas que, al explicar el universo y el destino del hombre, se tornan en sentimientos, mil veces más eficaces que el modesto saber demostrable. El espiritualismo ha cobrado vigor nuevamente, sobre todo a partir de la segunda década de nuestro siglo; la libertad de filosofar, el cultivo de las humanidades, la fe en la inteligencia, han sido más fuertes que el dogmatismo positivista. Esta quiso defender un orden estático en lo social y ahora recomienza una aventura más en la historia: la batalla entre agnósticos y creyentes. Una época de masas convierte en trasnochadas las élites liberales; la idea del Estado neutral se desvanece frente a la presión de los requirimientos sociales y a la necesidad de una política afirmativa. Después del siglo de predominio burgués hemos entrado 
de lleno al siglo de la masa, la cual es dogmática, exigente de mejoras elementales y generalmente despótica.

El derecho natural, que tuvo una fase teológica hasta el siglo diecisiete y una fase metafísica en los siglos del racionalismo, sufrió un breve eclipse durante el predominio positivista. Luego ha resurgido poderosamente para seguir inspirando la legislación en principios de libertad Y justicia. El positivismo analítico, cuyo representativo genial es Kelsen, no ha sido regocido por las instituciones políticas, las cuales mantienen su respeto por principios superiores al derecho dictado. El neo-tomismo o neo-escolaticismo, representxdo por Gény. Hauriou, Renard y Le Fur, funda el derecho natural en el pensamiento católico y supera el derecho natural racionalista de la escuela clásica, basado en el individualismo y aliado del capitalismo. El bien común y la justicia son las ideas que derivan directamente de la naturaleza del hombre en cuanto ser de razón. A la justicia legal debe suceder la justicia cocial, ligada por reglas eternas, de validez universal.

Examinemos ahora brevemente, los supuestos del Estado de Derecho, la crisis del poder político y la promesa contenida en el humanismo cristiano.

\section{El Estado de Derecho}

El progreso de la ciencia natural y de las matemáticas guarda relación con el florecimiento del racionalismo. Relegado durante la Edad Media a un segundo plano, por haber predominado la filosofía de la esencia, el racionalismo alcanza su completo desenvolvimiento a partir de Descartes. Este ve la esencia del hombre en el pensar y destaca la singularidad de cada persona. Tendencias monistas y tendencias pluralistas se enfrentan definidamente en la metafísica de entonces. Spinoza es la expresión más clara del monismo, en tanto que Leibnitz representa el pluralismo con su doctrina de las mónadas El pensamiento de Leibnitz tiene su continuación en las filosofías individualistas y personalistas. Para Descartes, la libertad no es arbitrariedad, sino que consiste en actuar por clara comprensión racional. El problema de la libertad es planteado como determinación por la razón: la voluntad sigue a la ilumi. nación del entendimiento, el cual ordena los sentimientos y las pasiones.

La fórmula del subjetivismo racionalista de la libertad se debe a Kant, el cual lleva a su extremo la revolución cartesiana. El imperativo categórico se formula con la siguiente pauta: "obra solamente según una máxima tal que puedas querer al mismo tiempo que se tome ley universal". Como observa Sampay, el imperativo categórico está vacío de contenido y si lo adquiere es sólo por la generalización de una intención, o sea de un querer individual que se concreta en la máxima. La autonomía de la voluntad y el imperativo crtegórico son los sustitutos éticos de la filosofía cristiana. La voluntad racional del hombre se eleva a una voluntad legisladora universal; así se realiza el cambio del Decálogo por el imperativo categórico. De esta concepción se' 
seguirán la equivalencia de la legalidad con la moralidad y, posteriormente, el formalismo inauténtico de los positivistas.

Cincuenta años después de Kant, el liberalismo alemón, que fuera batido como partido político en 1848, logra compensarse por su progreso en el terreno jurídico. En éfecto, mientras en política alcanza sólo un constitucionalismo moderado, que aparece como concesión del Monarca, en el ćmbito jurídico logra imponer la concepción del Estado de Derecho, con lo que la autoridad queda subordinada a las reglas objetivas. La locución "Estado de Derecho" es empleada por primera vez por Von Mohl, en 1832, pero la concepción del "Rechtsstaat" o Estado de Derecho estaba en principio en la doctrina Kantiana que mira el Estado como Asociación civil jurídica destinada a actuar, cualquiera que sea su fin, dentro del marco del derecho. En "Principios metafísicos del Derecho" había formulado Kant, el primado del Derecho: "Tal es la única constitución permanente; aquella en la que la ley reina por sí misma y no depende de ninguna persona particular; tal es el último término del derecho público, el estado en el cual únicamente lo suyo puede ser atribuído perentoriamente a cada cual".

El desarrollo de dicha nota, o sea del Estado enmarcado por el derecho, ie debió especialmente a von Mohl, Gerber, Laband y Jellineck, los cuales configuraron una doctrina más concreta: la del Estado sometido al derecho. Gracias a ella se ha podido plantear que el estatismo es falso, rechazando la pretensión de los hegelianos de que el Estado debe absorber toda la vida de los individuos. Se ha definido que al Estado sólo le compete el orden externo, sin que pueda invadir la intimidad de la conciencia, y que "ningún cristiano puede vivir únicamente para el Estado, porque no puede renunciar $\alpha$ la eternidad de su destino", como expresa acertadamente Guido de Ruggiero.

\section{Iberalismo y Estado de Derecho}

La lógica del liberalismo ha sido estudiada admirablemente por John H. Hallowell, Guido de Ruggiero, Benedetto Croce y Luis Baudin. Su postulado esencial es el valor absoluto de la persona humana. Siendo los indiviauos entidades morales de igual valor no pueden someterse a ninguna voiuntad arbitraria, puesto que ello sería negar la dignidad moral que poseen como seres humanos dotados de razón. Pero, como quiera que la autoridad es necesaria para el orden social y para asegurar el respeto de los derechos individuales, el individuo se somete a una autoridad, siempre que ésta sea impersonal y objetiva. No se somete a la voluntad de otro individuo, sino a la autoridad impersonal de la ley.

La libertad que el liberalismo preconiza no está exenta de restricciones, pues ello sería licencia y no verdadera libertad. Es la libertad con responsabilidad, de acuerdo á la ley. Sobre las voluntades individuales se coloca la limitación basada en verdades etemas, en valores que trascienden $\alpha$ todos los individuos y que son descubribles por la razón. Como doctrina política derivada del individualismo, anota Hallowell, el liberalismo integral implica: a) La creencia de que el control social está asegurado mejor por el derecho 
que por las órdenes; así el individuo está gobernado por reglas impersonales y no sufre desmedro su dignidad; b) La creencia en un orden natural que comprende al individuo y a la colectividad o Estado; c) La creencia que hay una esfera de derechos, peculiares a los individuos en cuanto seres humcnos, esfera que el Estado no puede invadir y para cuya conservación existo el Estado.

De tales postulados, el liberalismo engendró la noción del Estado de Derecho, perfeccionada en nuestro siglo. El Estado de Derecho aparece como el servidor de la sociedad y no como su amo. El voluntarismo del gobernante nada vale; lo valioso es la regla objetiva e impersonal. La sumisión del poder al Derecho y la organización del Estado con miras a proteger los derechos de la persona son las dos notas esenciales del Estado de Derecho.

Ello quiere decir que el poder no sólo tiene límites que le señala el derecho positivo, los cuales puede franquear si alcanza a modificar la ley conforme el ordenamiento jurídico. Tiene sobretodo límites impuestos por el derecho natural, ya que el Estado ha sido instituido para asegurar la perfecta suficiencia de vida humana y contraría su fin si se opone a los derechos fundamentales del hombre. Igualmente, tiene límites que derivan del Derecho de Gentess, pues el Estado es parte de la comunidad internacional y está ligado a un orden de justicia universal impuesto por la razón humana. Este Derecho de Gentes, o sea el derecho natural aplicado a las relaciones internacionales, tuvo enunciación cabal en Vitoria: "Qued naturalis ratio inter omnes gentes constituit, vocatur jus gentium".

Por eso, lo importante es no sólo quien gobierna sino cómo gobierna. El gobierno debe ser legítimo por el origen de la autoridad y por la calidad ética de sus mandatos. De ahí que aún los gobiernos de facto miran en el asentimiento de los gobiernos su título de legitimidad. No pocas veces el asentimiento expresa el juicio realista del "mal menor", cuando los gobernartes no llenan el ideal querido, pero no existen otras posibilidades inmediatos. Mediante el imperio de la legalidad, que complementado por las decisiones te los tribunales constituye el régimen de juridicidad, el Poder queda sometido a reglas impersonales. El sentido y la finalidad del Estado radican en la protección debida a los derechos de la persona.

\section{Revisión Y subsistencia del Estado de Derecho}

La revisión que se viene haciendo de los supuestos teóricos del Estado te Derecho, sobre todo desde la primera guerra mundial, así como las convulsiones sociales operadas en los últimos años, demuestran que dicha fórmula política ha entrado en crisis. Ello se produjo por haber sobrevalorado el principio de libertad y el imperio de la ley formal. Antes que establecer usos nositivos del Estado, el liberalismo se propuso impedir los abusos del poder, ideal insuficiente para normar los grupos humanos y promover su bienestar El Estado liberal-burgués, que ponía énfasis en la libertad pero olvidaba el valor bienestar, está cediendo paso a un Estado protector de los económicamente débiles. Mediante la aplicación imparcial de la ley, los beneficios de la legislación social y los impuestos destinados a redistribuir la riqueza, el Esta- 
do de Derecho estó salvando su existencia $y$, con ella, la libertad de la persona humana.

Cabe preguntarse, en la actual etapa de convulsión social, si el Estado Ife Derecho ha logrado equilibrar el orden con la justicia y si la libertad política, esencial para que la democracia subsista es compatible con la elevación del nivel de vida para el mayor número.

En reciente estudio sobre las constituciones europeas de esta postjuerra, Boris Mirkine-Guetzévitch advierte con dolor que han sido escamoteadas las esperanzas de un Estado nuevo que alimentaran los hombres de la resistencia del tipo de Jacques Maritain. Con leves cambios de ropaje, subsiste la democracia anterior a la guerra, parlamentarista y burguesa, atomizada por los apetitos de partido. La transformación profunda, tantas veces anunciada, ha llegado sólo parcialmente. La crisis del pöder parece alentar a quienes sostienen la naturaleza mala del hombre y la necesidad de una avtoridad fuerte. La democracia, ha de ser mirada como una fe, al mismo tiempo que como una justificación racional de la sociedad libre. "El concepto de libertad es al mismo tiempo normativo e histórico: un demócrata sabe que el régimen libre es el mejor, que debe existir y que existiráa siempre porque la democracia no es sólo una ética sino también un devenir, una forma social que corresponde a la evolución humana". El peligro está en el Minotauro, llámese totalitarismo o democracia, o sea en el Estado omnipotente que deszonoce las funciones de la moral $y$ de las instituciones sociales, que enzuadrán las actividades del hombre y aminoran la intervención del poder.

Los pensadores de la época de la Ilustración, así como los convencionales franceses y quienes continuaron su fe en el progreso, creyeron en la perfectabilidad del hombre, la cual sería lograda gracias a las condiciones. cieadas por la democracia. Invocando tal precedente, Mirkine-Guetzévitch sostiene que no se puede ser demócrata y pesimista, que la democracia supone una mística sin la cual la política degenera en una mezquina lucha de intereses, ya sea de hombres o de grupos.

El sufragio universal no es sino uno de los elementos constitutivos de la democracia moderna; más importante que él es la defensa de la libertad, el respeto a la opinión pública, la función de control y censura que corresponde ejercer a las minorías, en suma, es el uso racional del poder.

La lucha por la democracia, o sea por un estado de hombres libres is "la búsqueda de una ética", ética social y ética individual. Bien entendida la democracia es un comportamiento, un empeño; si falta este empeño, la técnica constitucional es letra muerta".

De ahí la trascendencia de la tarea educadora en las Universidades, $x$ las que incumbe la formación de las élites. Decir docencia jurídica es afirmar una misión rectora para los maestros de Derecho: exponer el pensamiento jurídico-político en dos planos, o sea en el plano de la forma política real, de un lado y en el plano general del pensamiento. Esto último entraña la reducción de la política a los supuestos filosóficos sobre los que reposa el Estado. Ahora bien, explicar el pensamiento político-jurídico actual supone extender nuestro análisis más allá del campo puramente normativo; supone llegar hastá el confín histórico que limita el Estado modemo, hasta la entraña económica. 
y sociológica del hecho político, de aquella disputa de poder que origina para la humanidad una época dramática $\theta$ inquietante.

La quiebra de la posición más calificada del pensamiento liberal, o sea del positivismo y de la legalidad formal, señala el punto de madurez de la crisis. Hoy se enciende la polémica en una línea de ofensiva social, de emergencia humana que conmueve al mundo entero y que plantea a los intelectuales un deber, que es deber de decisión, como adelantados de una marcha hacia nuevas metas, hacia una fórmula política que se está gestando en la historia actual y que exige una alta tensión idealista.

\section{Humanismo Cristiano.}

Superando la ideología liberal, que hizo de la libertad contractual un dogma y abandonó la gran masa a la voracidad de la burguesía, se levanta hoy un movimiento de inspiración espiritualista, el humanismo cristiano, con la promesa de eliminar la violencia y de hacer triunfar la solidaridad humana sobre la prepotencia económica y sobre la desesperación que conduce al cclectivismo.

Se ha llevado a cabo en algunas naciones, con éxito notable, la conciliación del humanismo cristiano con el sistema de libre empresa; éste proporciona la técnica económica y queda en su verdadero papel, o sea como herramienta del espíritu. El humanismo cristiano, como se denomina hoy a la concepción del mundo sustentada en la metafísica religiosa de occidente, postula la dignidad del hombre en cuanto creatura de Dios y la vigencia de valores superiores como son la libertad y el bien. Como visión de la vida, trasciende a la economía y la subordina al cumplimiento del destino humano. En esta forma el liberalismo manchesteriano, henchido de utilitarismo, queda condenado por haber supueto un homo economicus sin base espiritual, y movido sólo por apetitos materiales, para el cual la riqueza constituyó el bien supremo.

Entre el doble escollo del liberalismo, que exalta el egoísmo burgués, y del socialismo, que concibe al Estado, como algo más valioso que la persona humana, el humanismo, cristiano viene luchando con éxito para que se distinga entre el capitalismo como productor y el capitalismo como distribuidor. En cuanto productor, el sistema de libre empresa ha probcto ser el que mejor estimula la creación de bienes, pero como distribuidor de la riquo $\mathrm{zat}$ ha sido culpable de grave egoísmo por no haber repartido equitativamente los bienes y por haber permanecido sordo a las exigencias del bienestar general. Que cada hombre alcance un mínimo de bienestar, sin el cual, como reconoce Santo Tomás, es casi imposible la práctica de la virtud: Tal es el objetivo del humanismo cristiano. Su fórmula podría ser: ni el Estado liberal, que asiste pasivamente al abuso social, ni el Estado totalitario, que oprime a la sociedad en nombre de una ideología gaseosa. El Estado no es sólo autoridad sino "cuerpo político", integrado por todos los asociados y dirigido a la promoción del bien común en cuanto este hace posible la realización de valores, como la justicia y la libertad, que trascienden la sociedad, o sea que se hallan más allá de ella, como justificativos meta-jurídicos. 


\section{Democracia y Capitalismo.}

Tal como analiza Kelsen en "Teoría Comunista del Derecho y del Estado', el concepto de democracia está siendo reinterpretado. En tanto la organización soviética distorsiona y desfigura la noción democrática, reduciéndola $\alpha$ un simulacro electoral en el que es impuesta la unanimidad, la organización capitalista se vale de la democracia para conservar gran parte de sus privilegios, pese a los cambios políticos operados con toda legalidad. Kelsen condena la identificación, pretendida por Lenin, de socialismo y democracia; por el contrario dice, el sistema capitalista está más próximo a la realización de la democracia económica mediante la libertad política, pues la presión de la mayoría va logrando pacíficamente la instauración de niveles mas altos de vida. Hacer pasar por democracia la dictadura del proletariado o el predominio sempiterno de los ricos, son vicios de identificación.

Respecto a la coexistencia de capitalismo y democracia, observa Kelsen: "Puede suceder que en un Estado capitalista cuya constitución es plencimente democrática, el proletariado no forme la mayoría del pueblo, o que a pesar de formar mayoría no haya una mayoría socialista o que existan dos o más partidos socialistas opuestos unos $\alpha$ otros. No cabe duda de que $\propto$ menudo sucede así, y ello explica por qué es posible una verdadera democrocia en un Estado capitalista. En esas circunstancias políticas, es una evidente ficción hablar de que la minoria, o sea la burguesía, oprime a la moyoría, es decir, al proletariado. En esas circunstancias políticas un movimiento revolucionario para la realización del socialismo puede conducir sólo a una verdadera dictadura, la dictadura de la minoría sobre la mayoría, y especialmente a la dictadura de un partido socialista".

Por reacción contra la idolatría del Poder, la segunda guerra mundial y el actual sistema político de Occidente se han dirigido a restaurar la concepción cristiana del Estado, distante del liberalismo clásico y del totalitarismo. La democracia liberal, que era aliada histórica del capitalismo por haber nacido en un movimiento burgués, tiende a ser sustituída por una democracia orgánica y cristiana, que sea promotora de una distribución do la riqueza más justa, haciendo participar de la renta nacional a todos los sectores sociales. Nuevamente se pone énfasis en afirmar que el hombre no debe estar subordinado al proceso económico sino que le corresponde dirigirlo para el bienestar general y que el Estado es un ente social y no una suma de átomos como pretendió el individualismo. Como advierten los egregios liberales Thomas Mann y Arnold Toynbee, la democracia tiende a conciliarse cen la justicia social para redimimos a la vez de la opresión política y de la miseria.

Lo verdaderamente valioso en la concepción del Estado de Derecho es haber afirmado la superioridad del Derecho sobre el Estado. Si acertamos. a enteder por Derecho, no solo la legislación establecida como quisieron los positivistas, sino tambiín un ideal de Justicia y preceptos éticos, entonces la. fórmula política del Estado de Derecho se convertirá en perfecta, hasta donde. cabe serlo a toda institución humana. 
La unión del liberalismo con el capitalismo ha obedecido a circunstoncias históricas y tiende a modificarse. Entendido como sistema de propiedad privada de los medios de producción, el capitalismo es uno de los elementos de la organización democrática, puesto que no cabe libertad política ahí en donde los medios de producción son propiedad colectiva, como en Ia Unión Soviética. Cuando el Estado es el único dador de trabajo, los individuos se hallan necesariamente esclavizados y la libertad sindical es imposible. Una bárbara represión aplasta toda oposición y hace imposible la alternabilidad en el poder. En cambio, en los países de organización democrática, la regulación de la actividad económica es tripartita; capital, trabajo y Estado equilibran su fuerza, con éxito que es patente en el camento creziente de la productividad y en la participación de más amplios sectores en la renta nacional. El constitucionalismo, que actualmente ensaya armonizar la democracia con la justicia social, rectifica el egoísmo económico y abandona el funesto "Iaissez faire, laissez passer". Las realizaciones logradas por Alemania Occidental y los Estados Unidos mediante un capitalismo progresista, que se ha visto obligado a humanizar la economía, son alentadoras.

La justicia salarial y la redistribución de la riqueza por medio de los impuestos han permitido a los países avanzados elevar el nivel general de vida y asegurar la subsistencia de la libertad. El Estado liberal-burgués va declinando en provecho de una organización democrática que concilia la libertad con el bienestar de la gran masa. El imperio de esta nueva concepcićn democrática va suprimiendo la explotación humana que la democracia irdividualista, inspirada en un liberalismo integral, no supo ni quiso eliminar. Como tradición de libertad, o sea en cuanto traduce la dignidad esencial del hombre, la democracia mantiene su vigencia. El constitucionalismo tiende hoy a rectificar el liberalismo económico, pero manteniendo a salvo la libertad política. El Estado de Derecho, sometido a las normas jurídicas, ha dado respuesta al problema de conciliar el orden y la libertad. Ahora se remoza activamente para que la relación de capital y trabajo asuma su verdadero sentido ético y para que la distribución de bienes redima a las masas de la ignorancia, de la desnutrición y de la miseria.

Por dinómica histórica nuestra organización seguirá reformándose, a fin de que los recursos económicos y los medios técnicos sirvan al bien del mayor número. Con inagotable energía espiritual, el hombre defiende la libertad; pero no sacrifica a ella la promesa de justicia económica. En toda la comunidad mundial se advierte un clamor por el pan y la cultura, en tanto el alma humana persiste adherida religiosamente a lo trascendente. iluminada desde el más allá. 